\title{
BRPKM
}
Buletin Riset Psikologi dan Kesehatan Mental http://e-journal.unair.ac.id/index.php/BRPKM e-ISSN: 2776-1851

ARTIKEL PENELITIAN

\section{Pengaruh Dukungan Sosial dan Harapan terhadap Resiliensi pada Remaja dengan Latar Belakang Keluarga Bercerai}

\author{
TASYA NABILAH NUR AZMY \& NURUL HARTINI * \\ Fakultas Psikologi Universitas Airlangga
}

\begin{abstract}
ABSTRAK
Penelitian ini bertujuan untuk mengetahui pengaruh dari dukungan sosial dan harapan dengan resiliensi pada remaja dengan latar belakang keluarga bercerai. Resiliensi dapat terbentuk karena dipengaruhi oleh faktor protektif yang dimiliki individu. Faktor protektif dapat bersifat internal yang mencakup harapan, dan bersifat eksternal yang mencakup dukungan sosial. Penelitian ini menggunakan pendekatan kuantitatif dengan metode survei dan melibatkan 451 partisipan yang berusia 13 hingga 22 tahun. Penelitian menggunakan alat ukur skala dukungan sosial, harapan, dan resiliensi. Hasil penelitian menunjukkan adanya pengaruh dari resiliensi terhadap dukungan sosial dan harapan, dengan nilai $p=$ $0,00<0,05$. Sedangkan nilai korelasi antar variabel menunjukkan hubungan antar variabel bersifat negatif, dengan nilai $r=-0,041$ pada dukungan sosial dan $r=-0,208$ pada harapan. Sehingga, dapat disimpulkan bahwa meningkatnya resiliensi disertai dengan menurunnya dukungan sosial dan harapan yang dimiliki remaja.
\end{abstract}

Kata kunci: dukungan sosial, harapan, resiliensi, remaja

\begin{abstract}
This study aims to determine the effect of social support and hope on resilience in adolescents with a divorced family. Resilience can be formed because the protective factors that individuals have. Protective factors have two types, by internal include hope and external include social support. This study used quantitative approach with survey method, and involved 451 participant, aged between 13 to 22 years. This study is used a scale measuring tool for social support, hope, and resilience scales. The results of this study show, between of social support and hope is influenced by the resilience, with a value of $\mathrm{p}=0,00<0,05$. The correlation value, shows that the relationship between variables is negative, with a value of $r=-0,041$ for social support and $r=-0,208$ for hope. It can be concluded that increased resilience is accompanied by decreased social support and hope of adolescents.
\end{abstract}

Keywords: adolescents, hope, resilience, social support.

Buletin Penelitian Psikologi dan Kesehatan Mental (BRPKM), 2021, Vol. 1(1), 621-628

*Alamat korespondensi: Fakultas Psikologi Universitas Airlangga, Kampus B Universitas Airlangga Jalan

Airlangga 4-6 Surabaya 60286. Surel: nurul.hartini@psikologi.unair.ac.id

Naskah ini merupakan naskah dengan akses terbuka dibawah ketentuan the Creative Common Attribution License (CC-BY-4.0) (http://creativecommons.org/licenses/by/4.0), sehingga penggunaan, distribusi, reproduksi dalam media apapun atas artikel ini tidak dibatasi, selama sumber aslinya disitir dengan baik. 


\section{PENDAHULUAN}

Keluarga merupakan unit terkecil dalam lingkungan hidup seseorang, yang terdiri dari ayah, ibu, dan anak yang dihubungkan dalam pertalian darah. Menjadi keluarga yang utuh dan bahagia tentunya menjadi harapan bagi setiap pasangan yang telah menikah, orang tua, dan anak untuk mewujudkan keluarga idealnya. Tetapi kenyataannya, sebagian dari beberapa keluarga di Indonesia harus menerima ketidakutuhan keluarganya. Perceraian dapat didefinisikan sebagai suatu peristiwa perpisahan secara resmi antara suami istri dan kesepakatan diantara mereka untuk tidak menjalankan tugas dan kewajibannya lagi selayaknya suami-istri (Dariyo, 2013 dalam Dewi dkk., 2014). Fenomena perceraian di Indonesia sendiri cukup marak terjadi. Berdasarkan data dari Badan Pusat Statistik Indonesia, angka kasus talak dan perceraian di Indonesia pada tahun 2018 mencapai 408.202 kasus (Badan Pusat Statistik, 2019). Dengan persebaran data yang terus meningkat dari tahun 2015 hingga 2018. Menurut Harjianto \& Jannah (2019), perceraian sebagai bentuk dari masalah sosial yang terjadi di masyarakat yang dipandang tidak sejalan dengan tujuan awal dari sebuah perkawinan. Adapun faktor yang mendukung terjadinya perceraian orang tua adalah faktor ekonomi, tanggung jawab, gangguan dari pihak ketiga, dan keharmonisan pasangan. Berdasarkan penelitian milik Nadeak (2014) yang menjelaskan bahwa terkait data mengenai struktur keluarga anak nakal, menyebutkan bahwa lebih dari separuh anak nakal berasal dari keluarga yang single parent atau orang tua tunggal. kemudian 19,5\% lainnya berasal dari keluarga broken home.

Pickar (2007 dalam Hidayat, 2019) menjelaskan bahwa anak dengan latar belakang keluarga bercerai secara signifikan lebih mungkin memiliki masalah emosional, sosial, dan akademis dibanding dengan anak yang memiliki keluarga utuh. Anak biasanya akan mengalami perasaan sedih, merasa sendiri, tidak mendapatkan kasih sayang yang layak, dan memiliki perasaan tertekan. Perasaan-perasaan tersebut mengarah kepada perasaan negatif yang membuat anak merasa ada pada situasi sulit (Widyastuti, 2017). Berbagai macam permasalahan akan muncul seiring berjalannya waktu sejak kedua orang tua memutuskan bercerai. Pada anak yang menginjak usia remaja akan merasakan permasalahan yang dihadapinya lebih kompleks. Hal ini ditegaskan oleh Emery (1999, dalam Dewanti \& Suprapti, 2014), bahwa seiring berjalannya waktu setelah perceraian, masa remaja menjadi masa yang paling sulit bagi anak-anak yang memiliki latar belakang keluarga bercerai. Hal tersebut dikarenakan masa remaja merupakan masa dimana individu mengalami perubahan substansial di semua bidang perkembangan. Remaja yang memiliki latar belakang perceraian dari kedua orang tuanya cenderung mengalami ketidakbahagiaan, kontrol diri yang rendah, dan tidak memiliki kepuasan dalam hidup (Nuraeni \& Setiawan, 2019).

Tetapi perlu digaris bawahi bahwa tidak semua anak dengan latar belakang keluarga bercerai akan mengalami depresi ataupun terjerumus ke dalam perilaku negatif tersebut. Sebagian anak dengan orang tua bercerai akan menjadikan perceraian kedua orang tuanya sebagai motivasi dan harapan kedepannya untuk membangun hubungan yang lebih baik dan mencegah agar terhindar dari pengalaman buruk yang dialami kedua orang tuanya di masa yang akan datang (Hadianti dkk., 2017). Resiliensi merupakan kemampuan yang membuat individu mampu bertahan dan tetap dapat bergerak maju dalam kondisi sulit sekalipun (Ungar, 2008). Resiliensi juga dapat diartikan sebagai bentuk kemampuan individu dalam menghadapi kesulitan-kesulitan dan tekanan yang menghampiri hidupnya, serta belajar untuk beradaptasi pada keadaan tersebut dan bangkit untuk memulai kehidupan yang lebih baik (Salim, 2018). Resiliensi yang dimiliki individu dapat berkembang karena faktor-faktor yang mempengaruhi hal tersebut. Faktor tersebut terbagi menjadi dua, yaitu faktor protektif dan faktor

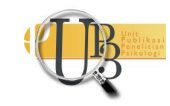


risiko. Kedua faktor tersebut dinilai berlawanan arah, dimana faktor protektif memiliki cara kerja untuk melindungi diri agar faktor risiko yang dapat menyebabkan remaja tidak mampu bertahan dan memunculkan simptom stres dalam dirinya (Rodgers \& Rose, 2002). Penelitian sebelumnya, milik Cathlin dkk., (2019) menjelaskan bahwa faktor protektif dalam diri individu berfungsi untuk mengurangi atau menghilangkan efek traumatis pada diri individu. Selanjutnya dijelaskan juga dari penelitian milik Yulivia (2016), bahwa faktor protektif dapat membantu individu dalam melakukan penyesuaian diri di masa-masa kritisnya.

Faktor protektif tersebut, terbagi menjadi dua yaitu faktor protektif yang bersifat internal dan bersifat eksternal. Faktor protektif internal salah satunya adalah kapasitas kognitif yang dimiliki individu mencakup harapan. Harapan dijelaskan sebagai kapasitas kognitif didasarkan pada perasaan yang diterima individu yang mana diturunkan secara langsung dari motivasi yang diciptakan dan jalur yang telah ditetapkan. Selanjutnya, pada faktor protektif eksternal salah satunya adalah dukungan sosial. Dukungan ini berasal dari orang-orang terdekat individu, misalnya teman dan keluarga. Hubungan atribut dukungan sosial dan harapan tersebut mengarah kepada faktor protektif yang dapat membantu membentuk proses resiliensi pada remaja dengan latar belakang keluarga bercerai. Bahwa ketika remaja memiliki harapan yang baik atas masa depannya dan disertai dengan dukungan dari lingkungannya yang baik pula, maka remaja akan membentuk sifat resilien dalam dirinya.

Dipilihnya dukungan sosial dan harapan sebagai variabel independen pada penelitian ini berdasarkan pada penjelasan mengenai faktor protektif yang membentuk resiliensi oleh Cathlin dkk. (2019). Selain itu dikarenakan menurut Nurjanah \& Diantina (2018), dukungan sosial dibentuk karena adanya hubungan baik yang diterima remaja dari lingkungannya, seperti penerimaan atas diri remaja yang tidak memiliki keluarga utuh karena perceraian kedua orang tuanya. Sedangkan menurut Cahyani \& Rahmasari (2019), harapan dibentuk karena remaja memiliki cita-cita, tujuan hidup, dan tekad berupa semangat untuk terus bergerak maju, serta kemampuan dalam diri individu dalam mencapai tujuan yang diinginkan. Faktor protektif tersebutlah yang bergerak untuk mencegah berkembangnya faktor risiko dalam diri remaja saat menghadapi masa sulit akibat perceraian kedua orang tuanya.

\section{Desain Penelitian}

\section{METODE}

Pada penelitian ini, penulis menggunakan pendekatan penelitian kuantitatif dengan metode survei. Tipe penelitian kuantitatif mengkaji fenomena secara kuantitatif, dimana penguatan dan objektivitas dalam penelitian tipe kuantitatif menggunakan data angka dan analisis yang terstruktur dan terkontrol (Azwar, 1998). Pada penelitian ini, penulis menggunakan jenis penelitian survei. Metode yang digunakan adalah metode survei, dimana bertujuan untuk menanyakan responden mengenai kepercayaan mereka, opini, karakteristik, dan perilaku masa lalu ataupun masa sekarang (Neuman, 2014). Pengambilan data dilakukan dengan cara menyebar kuisioner online melalui Google Form.

\section{Partisipan}

Partisipan dalam penelitian ini adalah pria dan wanita, berusia 13 hingga 22 tahun, dan memiliki latar belakang keluarga bercerai (kedua orang tua bercerai). Teknik sampling pada penelitian ini menggunakan teknik non-random sampling dengan convenience sampling. Penulis menggunakan teknik ini karena pemilihan sampel dapat diberikan kepada siapa saja yang mudah dijangkau dan bersedia. Kemudian, penulis akan memilih sampel yang sesuai dengan kriteria untuk menjadi responden penelitian (Neuman, 2014). Teknik perhitungan sampel yang digunakan pada penelitian ini menggunakan rumus dari perspektif Tabachnick dan Fidell, yaitu $\mathrm{N}>50+8 \mathrm{~m}$ (Pallant, 2011). 
Berdasarkan rumus tersebut, dapat diketahui bahwa jumlah sample yang dibutuhkan pada penelitian ini sebesar 66 orang. Penelitian ini melibatkan 451 partisipan $\left(M_{\text {usia }}=18,5 ; S D_{\text {usia }}=1,92\right)$. Latar pendidikan pada partisipan Sekolah Menengah Pertama sebanyak 13 orang (3\%), Sekolah Menengah Atas sebanyak 159 orang (35\%), Diploma sebanyak 44 orang (10\%), Sarjana sebanyak 230 orang (51\%), dan tidak ada keterangan sebanyak 5 orang (1\%).

\section{Pengukuran}

Pada penelitian ini, variabel dukungan sosial berdasarkan komponen dukungan sosial dari teori Sarafino (1990) dengan alat ukur yang dirancang oleh Hidayat (2019). Terdiri dari 29 aitem menggunakan skala likert dengan 5 pilihan jawaban (1= "sangat tidak setuju", $5=$ "sangat setuju"). Kemudian untuk variabel harapan menggunakan alat ukur yang dirancang oleh Hidayat (2019) berdasarkan komponen harapan dari teori Lopez \& Snyder (2002). Terdiri dari 24 aitem menggunakan skala likert dengan 5 pilihan jawaban (1= "sangat tidak setuju", 5= "sangat setuju"). Selanjutnya untuk variabel resiliensi menggunakan alat ukur yang dirancang oleh Hidayat (2019) berdasarkan aspek resiliensi dari teori Connor dan Davidson (2003). Terdiri dari 31 aitem menggunakan skala likert dengan 5 pilihan jawaban ( 1 = "sangat tidak setuju", 5= "sangat setuju").

Validitas pada penelitian ini menggunakan validitas isi (content validity) yang merujuk pada aitem pertanyaan berdasarkan alat ukur. Untuk mencapai validitas isi diperlukan bantuan dari professional judgement atau orang yang berkompeten dalam bidang yang diteliti. Reliabilitas pada penelitian ini menggunakan reliabilitas Alpha Cronbach dan diperoleh nilai reliabitas pada dukungan sosial sebesar $\alpha=0,85$, pada harapan sebesar $\alpha=0,835$, dan resiliensi sebesar 0,77 .

\section{Analisis Data}

Teknik analisis pada penelitian ini menggunakan teknik regresi linear berganda dan melalukan uji asumsi terlebih dahulu. Uji asumsi yang dilakukan adalah uji normalitas, uji linearitas, uji multikolinearitas, dan uji heteroskedastisitas. Pengolahan data pada proses analisis data menggunakan bantuan dari aplikasi IBM SPSS Statistics 22 for Windows.

\section{HASIL PENELITIAN}

Hasil uji korelasi bivariet pearson menunjukkan hubungan negatif antara variabel dukungan sosial terhadap resiliensi dengan perolehan nilai $\mathrm{r}=-0,212 ; p=0,000$. Begitupun uji korelasi pada variabel harapan terhadap resiliensi, menunjukkan hubungan negatif dengan perolehan nilai $r=-0,372 ; p=0,000$.

Selanjutnya, hasil regresi menunjukkan adanya pengaruh yang signifikan dari dukungan sosial dan harapan terhadap resiliensi pada remaja dengan latar belakang keluarga bercerai sebesar $14,7 \%(\mathrm{~F}(2$, 448)=38,752; $p=0,000 ; \mathrm{R}^{2}=0,147$ ). Kemudian untuk analisis independent $t$ test, menunjukkan bahwa dukungan sosial berpengaruh terhadap resiliensi pada remaja dengan latar belakang keluarga bercerai $(t(448)=-2,16 ; p=0,031)$. Pada variabel harapan juga menunjukkan pengaruh terhadap pembentukan resiliensi yang dimiliki remaja dengan latar belakang keluarga bercerai $(t(448)=-7,33 ; p=0,00)$.

\section{DISKUSI}

Penelitian ini bertujuan untuk melihat adanya pengaruh antara dukungan sosial dan harapan terhadap resiliensi. Berdasarkan hasil penelitian di atas dapat diuraikan bahwa apabila remaja yang kedua orang tuanya bercerai akan mendapatkan kemampuan resiliensinya dari dukungan sosial dan harapan yang 
diterimanya. Artinya hipotesis satu pada penelitian ini diterima. Penelitian ini sejalan dengan penelitian milik Hidayat (2019) yang mengatakan bahwa dukungan sosial dan harapan secara signifikan memberikan pengaruh terhadap resiliensi pada remaja. Penelitian ini juga didukung oleh penelitian milik Rizkina (2018) yang mengatakan bahwa dukungan sosial dan harapan menjadi atribut yang memiliki nilai signifikansi paling mempengaruhi resiliensi. Pada penelitian ini menunjukkan bahwa harapan sebagai faktor protektif yang bersifat internal datang dari dalam diri individu. Ketika remaja memiliki cita-cita, motivasi, dan tujuan hidup yang baik, maka remaja akan membangun harapan dalam dirinya. Harapan yang dibentuk remaja yang kedua orang tuanya bercerai mengarah pada motivasi untuk membentuk hubungan baik di masa yang akan datang dan menjadikan perceraian kedua orang tuanya sebagai pengalaman di masa lalu yang tidak ingin terulang kembali (Hadianti dkk., 2017).

Pada penelitian ini juga menunjukkan bahwa harapan sebagai faktor protektif yang bersifat internal datang dari dalam diri individu. Ketika remaja memiliki cita-cita, motivasi, dan tujuan hidup yang baik, maka remaja akan membangun harapan dalam dirinya. Harapan yang dibentuk remaja yang kedua orang tuanya bercerai mengarah pada motivasi untuk membentuk hubungan baik di masa yang akan datang dan menjadikan perceraian kedua orang tuanya sebagai pengalaman di masa lalu yang tidak ingin terulang kembali (Hadianti dkk., 2017). Sedangkan pada dukungan sosial menunjukkan bahwa resiliensi dapat dipengaruhi oleh faktor protektif yang bersifat eksternal. Ketika remaja mendapatkan dukungan, dorongan, dan semangat dari lingkungan disekitarnya, maka remaja akan merasa bahwa hidupnya berarti. Peran keluarga besar, lingkungan sekolah, dan teman-teman dekat remaja mampu membuat remaja mengalihkan pikiran remaja akibat perceraian orang tuanya (Dewi dkk., 2014). Hal tersebut yang mendukung pembentukan resiliensi dalam diri remaja yang kedua orang tuanya bercerai.

Hasil analisis hipotesis dua pada penelitian ini diterima dan sejalan dengan penelitian sebelumnya milik Hadianti dkk. (2017) yang mengemukakan bahwa kemampuan resiliensi pada remaja dengan latar belakang keluarga bercerai dapat terbentuk dari diri sendiri, lingkungan keluarga, dan lingkungan sosial. Bentuk lingkungan sosial dijelaskan sebagai bentuk dukungan sosial dari lingkungan terdekat individu, seperti misalnya layanan konseling khusus yang disediakan pihak sekolah untuk individu dengan latar belakang orang tua yang bercerai. Selanjutnya, hasil analisis hipotesis tiga pada penelitian ini diterima dan didukung oleh penelitian milik Detta \& Abdullah (2017) yang menjelaskan bahwa, harapan yang dibangun remaja ketika kedua orang tuanya bercerai adalah berasal dari hubungan baik yang diciptakan remaja dengan lingkungannya. Selain itu, proses mendekatkan diri yang dilakukan remaja kepada Tuhannya dinilai mampu menciptakan harapan baik dan positif pada remaja saat mengalami kesulitannya. Hal ini menunjukkan bahwa harapan yang positif akan membantu individu untuk terus bergerak maju ke arah yang lebih positif dalam masa-masa sulitnya.

\section{SIMPULAN}

Melalui hasil penelitian ini dapat disimpulkan bahwa dukungan sosial dan harapan secara parsial berpengaruh terhadap resiliensi remaja dengan latar belakang keluarga bercerai. Maka resiliensi pada remaja dengan kedua orang tua bercerai dapat dibentuk karena adanya faktor protektif yang bekerja sebagai pelindung dalam mencegah faktor risiko berkembang dalam diri remaja. Faktor protektif ini dihasilkan dari dalam diri individu (internal) ataupun luar individu (eksternal). Faktor internal ini salah satunya dibentuk karena adanya harapan dalam diri individu untuk mencapai tujuan yang diharapkan, yaitu menghilangkan pengalaman traumatis akibat perceraian kedua orang tuanya. Faktor protektif internal juga didukung oleh faktor protektif eksternal, yang bekerja dari luar diri individu, salah satunya adalah dukungan sosial. Dukungan sosial yang diterima remaja didapatkan dari lingkungan terdekat, seperti keluarga besar, teman-teman remaja, dan lingkungan sekolah. Sehingga ketika remaja memiliki 
dukungan sosial yang baik dari lingkungannya, remaja akan mampu mengalihkan pikiran dan rasa sedihnya akibat akibat perceraian kedua orang tuanya.

Saran yang dapat penulis berikan untuk remaja yang memiliki latar belakang keluarga bercerai, diharapkan nantinya mampu bertahan di masa-masa sulitnya dengan cara mencari dukungan sosial sebanyak-banyaknya dan menciptakan harapan-harapan baru dari lingkungan di sekitarnya. Selanjutnya, bagi pembaca yang membaca penelitian ini dan dirasa ada remaja yang menjadi korban perceraian kedua orang tuanya di sekitar pembaca, harap untuk segera dibantu. Bantuan yang diberikan bisa berupa dukungan emosional seperti empati, perhatian, dan kepedulian agar remaja tidak merasakan kesendirian dalam menghadapi masa-masa sulitnya.

\section{UCAPAN TERIMAKASIH}

Terima kasih kepada Allah SWT, karena atas izin-Nya, naskah ini dapat diterbitkan. Terima kasih kepada semua orang yang sudah terlibat dalam penulisan naskah skripsi ini. Kepada dosen pembimbing saya, Bu Nurul. Serta kepada dosen penguji saya, Bu Wiwin dan Bu Rini. Serta kepada Ayah, Ibu, Kakak, dan Adik saya. Terima kasih juga kepada Kak Novi atas izinnya menggunakan alat ukur penelitiannya untuk digunakan pada penelitian ini, serta seluruh responden dalam penelitian ini.

\section{DEKLARASI POTENSI TERJADINYA KONFLIK KEPENTINGAN}

Tasya Nabilah Nur Azmy tidak bekerja, menjadi konsultan, memiliki saham, atau menerima dana dari perusahaan atau organisasi manapun yang mungkin akan mengambil untung dari diterbitkannya naskah ini.

\section{PUSTAKA ACUAN}

Azwar, S. (1998). Metode Penelitian (1st ed.). Yogyakarta: Pustaka Pelajar.

Badan Pusat Statistik. (2019). https://www.bps.go.id/linkTableDinamis/view/id/893

Cahyani, Y. U., \& Rahmasari, D. (2019). Resiliensi pada Remaja Awal yang Orangtuanya Bercerai. Indonesian Psychological Research, 1(2), 36-44. https://doi.org/10.29080/ipr.v1i2.186

Cathlin, C. A., Anggreany, Y., \& Dewi, W. P. (2019). Pengaruh Harapan Terhadap Resiliensi Wanita Dewasa Muda Yang Pernah Mengalami Abortus Spontan. Jurnal Psikologi Ulayat, 6, 1-13. https://doi.org/10.24854/jpu02019-106

Connor, K. M., \& Davidson, J. R. T. (2003). Development of a new Resilience scale: The Connor-Davidson Resilience scale (CD-RISC). Depression and Anxiety, 18(2), 76-82. https://doi.org/10.1002/da.10113

Detta, B., \& Abdullah, S. M. (2017). Dinamika Resiliensi Remaja Dengan Keluarga Broken Home. Insight: Jurnal Ilmiah Psikologi, 19(2), 71. https://doi.org/10.26486/psikologi.v19i2.600

Dewanti, \& Suprapti. (2014). Resiliensi remaja putri terhadap problematika pasca orang tua bercerai.

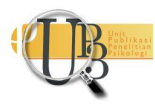


Jurnal Psikologi Pendidikan Dan Perkembangan, 3(3), 164-171.

Dewi, Nadia Refilia, \& Hendriani, W. (2014). Faktor protektif untuk mencapai resiliensi pada remaja setelah perceraian orangtua. Psikologi Kepribadian Dan Sosial, 03(03), 38-39. http://journal.unair.ac.id/downloadfull/JPKS8891-77aabf9ceefullabstract.pdf

Hadianti, S. W., Nurwati, N., \& Darwis, R. S. (2017). Resiliensi Remaja Berprestasi Dengan Latar Belakang Orang Tua Bercerai. Prosiding Penelitian Dan Pengabdian Kepada Masyarakat, 4(2), 223-229. https://doi.org/10.24198/jppm.v4i2.14278

Harjianto, H., \& Jannah, R. (2019). Identifikasi Faktor Penyebab Perceraian Sebagai Dasar Konsep Pendidikan Pranikah di Kabupaten Banyuwangi. Jurnal Ilmiah Universitas Batanghari Jambi, 19(1), 35. https://doi.org/10.33087/jiubj.v19i1.541

Hidayat, N. (2019). Pengaruh Dukungan Sosial dan Harapan terhadap Resiliensi Pada Remaja. Universitas Negeri Yogyakarta.

Lopez, S. J., \& Snyder, C. R. (2002). Handbook of Positive Psychology (2nd ed.). Oxford University Press, USA.

Nadeak, T. F. S. (2014). Fenomena “Anak Nakal” di Rungkut Surabaya. Vol. 02 No. 02.

Neuman, L. W. (2014). Basic of Social Research: Qualitative \& Quantitative Approach (3th ed., P). Pearson Education Limited.

Nuraeni, N., \& Setiawan, A. (2019). Sikap Remaja Yang Mengalami Broken Home : Studi. 3(3), 137-149.

Nurjanah, A., \& Diantina, F. P. (2018). Korelasi Dukungan Sosial dengan Resiliensi pada Individu Korban Perceraian. Prosiding Psikologi, 773-778.

Pallant, J. (2011). SPSS Survival Manual website. 359.

Rizkina, S. (2018). Pengaruh Dukungan Sosial dan Harapan terhadap Resiliensi Anak Didik Lapas Kelas IIA SAlemba. Jurnal Raudhah, 06(02), 1-15.

Rodgers, K. B., \& Rose, H. A. (2002). Risk and resiliency factors among adolescents who experience marital transitions. Journal of Marriage and Family, 64(4), 1024-1037. https://doi.org/10.1111/j.1741-3737.2002.01024.x

Salim, M. A. (2018). Hubungan Antara Harapan dan Resiliensi dengan Depresi pada Penderita Kanker Wanita. Universitas Islam Negeri Sultan Syarif Kasim Riau.

Sarafino, E. P. (1990). Health Psychology: Biopsychosocial Interactions. John Wiley and Sons.

Ungar, M. (2008). Resilience across cultures. British Journal of Social Work, 38(2), 218-235. https://doi.org/10.1093/bjsw/bcl343

Widyastuti, T. (2017). Resilience of a Child From Broken-Home Family: a Phenomenology Study. IJASOS-

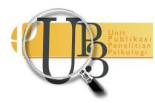


International E-Journal of Advances in Social Sciences, III(9), 1024-1034. https://doi.org/10.18769/ijasos.370052

Yulivia, E. (2016). Hubungan antara Faktor Protektif Eksternal dengan Penyesuaian Diri pada Remaja. 